\title{
E. P. Thompson e a pesquisa em Ciências Sociais
}

\author{
Maria Célia Marcondes de Moraes* \\ Ricardo Gaspar Müller**
}

\section{Resumo}

E. P. Thompson desenvolveu um importante diálogo entre as Ciências Sociais ao incorporar em suas pesquisas históricas categorias sociológicas e ao criticar as tendências funcionalistas de ambas as disciplinas, a Sociologia e a História. Seu método para analisar a formação da classe trabalhadora representa uma crítica simultânea às leis e regras metodológicas de historiadores sociais e sociólogos conservadores, funcionalistas e marxistas ortodoxos. A atualidade da obra de Thompson reside no fato de que seu pensamento é uma defesa da razão e dos fundamentos ontológicos do real, um forte contraponto ao ceticismo epistemológico, à visão relativista que nega a possibilidade do conhecimento objetivo e ao anti-realismo correntes. As proposiçôes thompsonianas têm a disciplina histórica como referência e orientam a reflexão acerca da pesquisa sociológica e das questôes político-sociais contemporâneas. Assim, os objetos da pesquisa sociológica, sem perder seu caráter específico, só ganham inteligibilidade se forem compreendidos em seu movimento histórico. É esta percepçáo de pesquisa que baliza os argumentos do artigo e reconhece Thompson como um interlocutor privilegiado.

Palavras-chave: Ciências Sociais-Pesquisa. Interação social.

* Doutora em Educação pela Pontifícia Universidade Católica do Rio de Janeiro (PUC). Pós-Doutorado pela University of Nottingham. In memoriam.

** Doutorado em História Social pela Universidade de São Paulo (USP). Pós-Doutorado pela Universidade Federal do Rio de Janeiro. Professor do Centro de Filosofia e Ciências Humanas, Departamento de Sociologia e Ciência Política da Universidade Federal de Santa Catarina (UFSC). 
De fato, a práxis humana dirige-se por necessidade ao ser das coisas. Do que se segue, por um lado, que as questóes ontológicas na verdade nunca podem ser ignoradas; por outro, e mais importante, que, sendo o mundo um complexo estruturado, a práxis humana não pode limitar-se ao ser imediato, empírico, das coisas. Nem o mundo natural se esgota no fenomênico, no empírico, nem o mundo social se esgota em sua última forma, da qual toda a gênese histórica parece apagada, como disse Marx.

Mário Duayer

\section{Introduçáo}

Nos últimos anos, pesquisadores (AHMAD, 1992, 2002, 2007; SEARLE, 1998; HAACK, 1997; BHASKAR, 1986, 1993, 1997; CALLINICOS, 2006; CARDOSO, 1988, 1997, 2001; DUAYER, 2001, 2003, 2006; EAGLETON, 2003; JAY, 2006; NORRIS, 1996, 1998; MORAES, 2001, 2003, 2007, entre outros), têm buscado oferecer elementos objetivos para a compreensáo do projeto político e epistemológico que promove o achatamento do mundo, reduzindo o horizonte do conhecimento à experiência sensível. Avilta-se, assim, a pesquisa em Ciências Sociais particularmente a sociológica - por transformá-la em simples levantamento de dados empíricos, em desenvolvimento de instrumentos de controle desses dados com vistas a descrever seu provável comportamento futuro, em estratégia de intervenção, ou ainda, em suas versōes "pós", como narrativas fragmentadas, descriçōes vulgares das múltiplas faces do cotidiano social.

Nessa mesma linha, os pesquisadores denunciam o ceticismo epistemológico contemporâneo em seus diversos feitios e sutilezas. Vislumbram-se, por certo, sinais de esgotamento de seus representantes mais notáveis, mas "na teoria" (pós-modernismo, pós-estruturalismo, neopragmatismo e desconstruçáo), ainda exercem influência para além de um pequeno público ilustrado ou acadêmico, interferindo, ainda que de forma mediada, nos debates em esferas culturais e sociopolíticas mais amplas (NORRIS, 1996, p. 7). Esses pesquisadores atestam que o ceticismo epistemológico persiste e, acompanhado de crescente anti-realismo e 
relativismo, empobrece a compreensão de ciência e esmaece a abrangência, a força e a profundidade do campo gnosiológico. No mais das vezes, o alcance do cognoscível restringe-se ao vocabulário da prática e submete-se às crenças socialmente justificadas, ao campo da persuasão, das formas de comunicação e de conversação (MORAES, 2001b, 2007). Conhecemos o que construímos. Nesse contexto, ocorre a confusão entre ceticismo epistemológico e relativismo ontológico. Nossos conhecimentos são relativos, porque são sociais, históricos, contextualizados, conjunturais, culturais, etc., e desse caráter transitório e relativo de nosso conhecimento infere-se que ele não pode ser objetivo, será sempre um ponto de vista individual, de um grupo, de uma cultura. Dito de outro modo, do relativismo epistemológico deduz-se o relativismo ontológico, ou seja, da "[...] concepção de acordo com a qual idéias, teorias, etc. opostas não podem ser objetivamente comparadas porque, da mesma forma que a beleza está nos olhos de quem ama, a verdade está na ótica de quem a afirma” (DUAYER, 2006, p. 120) conclui-se a impossibilidade da verdade, a negação do real, do racional, da objetividade, enfim, da própria cognição do real. E se o conhecimento não pode ser neutro, por conseguinte, não pode também ser objetivo (MORAES, 2007, p. 2).

Nessa perspectiva cética e relativista, o mundo social é esvaziado de qualquer dimensão estrutural duradoura que apenas o esforço teórico pode alcançar. Por conseguinte, a teoria que se constrói, nivelada em seu conjunto por indiferenciado relativismo, restringe-se a descrever e, quando muito, a nomear as formas fenomênicas do cotidiano (MORAES, 2007). Nas palavras de Soares (2007, p. 43),

[...] do truísmo de que nossas crenças significam o mundo para nós, pois são sempre sociais, históricas, culturais, e por isso mesmo, relativas, desdobra-se a idéia de que não há como escolher racionalmente entre elas e, neste sentido, não haveria possibilidade de um conhecimento objetivo sobre o mundo de uma aproximação gradativamente mais adequada da realidade. Da negaçáo da verdade enquanto dogma, desprende-se a idéia de que não há verdade.

Como se sabe, as experiências com alguma possibilidade científica dependem da atividade experimental ou sensorial, quer dizer, têm como alicerce o papel dos seres humanos, seja como agentes causais, seja como 
aqueles que percebem. É com base nos fenômenos empíricos abstratos que a pesquisa pode chegar a compreender sua essência conceitual (GOLDMANN, 1979; MORAES, 2000), pois é nos movimentos mais simples da vida cotidiana que se situa o início do processo de compreensão do ser social em seu sentido ontológico (MORAES; MÜLLER, 2005). No entanto, no dia-a-dia a complexidade da realidade social se apresenta em termos muito deformados, pois, como lembra Marx (1974, p. 42), em sua vida diária o ser humano é movido por suas necessidades de sobrevivência "do estômago e da fantasia”. Ou seja, se aquilo que caracteriza o empírico é subjetivo, é o que é capturado pelas percepçóes do sujeito, então o entendimento do mundo limita-se ao que ele percebe. Dessa forma,

[...] a noção contida no conceito de mundo empírico é antropocêntrica, pois postula que o mundo é o que os seres humanos podem experimentar. Nessa perspectiva, não se percebe que para a experiência ser significativa para a ciência é preciso que se reconheça a atividade social que a antecede. (ÁVILA, 2007, p. 20).

Por isso, informa Lukács (1979, p. 32), é necessário que o ponto de partida do conhecimento se constitua em uma abstração correta, que em sua estrutura interna já possua características da pesquisa científica. Filosofia e ciência originam-se na vida cotidiana, desenvolvem-se como instâncias autônomas para, finalmente, retornar à práxis imediata e informá-la com novas ou melhores concepçóes. $\mathrm{O}$ aprofundamento teórico, possibilitado pelas formas mais sofisticadas de conhecimento, permite um alargamento do escopo da práxis humana, fazendo com que o que se apresentava como um paradoxo à experiência imediata passe a ser compreendido como verdade científica (MORAES, 2007). Marx (1865) assinala que é um paradoxo que a “[...] terra se mova em volta do sol e que a água seja constituída por dois gases altamente inflamáveis. A verdade científica é sempre um paradoxo do ponto de vista da experiência imediata que alcança apenas a mistificada aparência das coisas". Assim, a teoria não deve abandonar seu lugar catalisador, e nem poderia ser de outra forma, assinala Duayer (2003), uma vez que, em um mundo cada vez mais complexo, teorizar é um imperativo da prática.

Como se vê, não são de pouca monta as questôes que apontam o norte das discussóes teórico-metodológicas na Sociologia nos dias de hoje. 
Este trabalho se propóe a contribuir para o debate, lembrando um dos mais interessantes e controversos pensadores do século XX, o historiador inglês Edward Palmer Thompson, o qual, de nosso ponto de vista, já a seu tempo, antevia os problemas acima assinalados e jamais renunciou à base ontológica de sua pesquisa. Mas, cabe indagar, por que sua obra interessaria a este debate?

\section{Thompson: ontologia e crítica}

A singular contribuição de E. P. Thompson é seu anseio teórico e político de relacionar e aproximar criticamente a Filosofia e as Ciências Sociais (especialmente História, Antropologia e Sociologia) e seu engajamento político. Sua contribuição, portanto, pode ser observada em diferentes áreas acadêmicas e campos temáticos, como os dos estudos de formação de classe e de movimentos sociais, que tendem a exigir rupturas de fronteiras e mediações teóricas mais sistemáticas.

Os estudos de Thompson valorizam a importância da práxis envolvendo práticas, experiências, aspiraçóes e valores (comunitários, religiosos, etc.) da classe trabalhadora. Dessa forma, um dos aspectos fundamentais do método de Thompson é sua capacidade de formar objetivos e aspiraçóes para aqueles submetidos a circunstâncias políticas adversas, mas que precisavam estabelecer e defender sua própria opiniāo política. Desse modo, para ele, um dos princípios básicos de uma análise reside na habilidade de articular a teoria a processos diferentes e em constante mudança.

Para Thompson, o dissenso, os movimentos de oposição podem obter vantagens e direitos efetivos para a classe trabalhadora. Tal noção de dissenso implicou, em primeiro lugar, um confronto com as correntes comunistas então hegemônicas, que não admitiam mudanças de perspectiva na ortodoxia estabelecida. Em segundo, articulados à noção de dissenso, o método e as categorias propostos por Thompson questionam as abordagens ortodoxas de pesquisa das relaçóes sociais e dos mecanismos de interação humana.

Além de seu trabalho teórico e historiográfico, Thompson desenvolveu também uma intensa atividade política orientada por sua concepção de socialismo e pela defesa de seus ideais. Sua presença em movimentos pacifistas - e na organização de documentos, ensaios e livros - revelou como seu ideal de marxismo estabeleceu um núcleo de 
convergência de uma tradição de crítica e de práxis radicais. Seu ativismo político e as constantes polêmicas em que esteve envolvido, associados à importância atribuída aos temas relacionados à luta dos trabalhadores e sua contribuição intelectual para a elaboração de uma "história vista de baixo", distinguem-no como um dos mais eloquentes e influentes historiadores e intelectuais socialistas ingleses.

Sua interpretação do materialismo histórico se distingue por articular, de forma construtiva, aspirações políticas e processo histórico. O pré-requisito dessa abordagem é o de que toda análise teórica deve ser apreendida na prática do "agir humano" e na medida do diálogo entre teoria e evidência, isto é, teoria e pesquisa empírica, sem abandonar a atuação política. A análise dos sujeitos envolvidos na construção de seus próprios destinos tornou-se o principal foco dos estudos de Thompson, definindo uma relação de compromisso entre sua própria atuação e o que ele acreditava ser um movimento histórico democrático. A partir desse compromisso e dessa crença, ele entende que toda política, história e teoria socialistas devem participar desse processo de democratização.

Inglis (1982, p. 199) assinala que Thompson nos ofereceu "um novo passado para viver", transformando "[...] a memória social, de modo que as pessoas definiram novas perspectivas, na medida em que puderam reinterpretar a formação do presente". Ou, como aponta Müller (2002, p. 14), porque Thompson exerceu oposição apaixonada à crescente desumanização das relações sociais, "[...] marca de sua contribuição ao que ele considerava o processo de luta popular por uma sociedade democrática. Ele reafirmou o materialismo histórico em seu caráter de teoria da emancipação humana, de constante renovação dos valores de uma cultura de dissidência”.

Agregue-se, também, sua importância para o desenvolvimento de uma concepção de história, a "história vista de baixo", fato que, segundo ele mesmo, muitas vezes o levou a ser complacente com aspectos conservadores dos movimentos populares (THOMPSON, 1980). ${ }^{1}$

Além disso, Thompson desenvolveu um importante diálogo entre as Ciências Sociais ao incorporar em suas pesquisas históricas categorias sociológicas, como também ao criticar as tendências funcionalistas de ambas as disciplinas, a Sociologia e a História. Nesse sentido, seu método para analisar a formação da classe trabalhadora pode ser visto como uma crítica às leis e regras metodológicas de historiadores sociais conservadores, de marxistas 
ortodoxos, bem como as dos sociólogos funcionalistas, responsáveis pelos "sistemas de estratificação", que pretendem explicar e justificar eventuais diferenças de classe. Thompson posicionou-se contra essas tendências enfatizando as relaçóes entre o humano e o histórico. A seu ver, classe é um fenômeno histórico, e não uma categoria rígida, cristalizada, tal como a compreendiam, de um lado, a ortodoxia marxista, e de outro, a Sociologia funcionalista. Em suas palavras:

Por classe, entendo um fenômeno histórico que unifica uma série de acontecimentos díspares e aparentemente desconectados, tanto na matériaprima da experiência como na consciência. Ressalto que é um fenômeno histórico. Não vejo a classe como uma "estrutura", nem mesmo como uma "categoria", mas como algo que ocorre efetivamente (e cuja ocorrência pode ser demonstrada) nas relaçóes humanas. Ademais a noção de classe traz consigo a noção de relação histórica. Como qualquer outra relação, é algo fluido que escapa à análise ao tentarmos imobilizá-la num dado momento e dissecar sua estrutura. A mais fina rede sociológica não consegue nos oferecer um exemplar puro de classe, como tampouco um do amor ou da submissão. A relação precisa estar sempre encarnada em pessoas e contextos reais [...]. (THOMPSON, 1987, p. 9-10, grifo no original). ${ }^{2}$

Com vistas a identificar os aspectos humanos das relaçóes de produção e a apreender a efetiva dimensão do antagonismo de classe, Thompson (1980, p. 226-230) julga útil, por exemplo, avaliar e comparar os conteúdos, os métodos e o significado de debates envolvendo noções como níveis salariais, padrão de vida, séries (históricas) de preços e seus resultados. Para ele, a medida da riqueza da classe trabalhadora da época não poderia ser julgada apenas em padróes quantitativos e, por esse motivo, considera que à visão reducionista escapam os aspectos qualitativos da vida da classe trabalhadora. Opóe-se, dessa forma, às interpretaçóes hegemônicas em seu tempo nos estudos sobre o tema (MÜLLER, 2002, p. 102, 120-121).

De todo modo, ao relacionar e integrar elementos teóricos e práticos do desenvolvimento da política radical na Grã-Bretanha, Thompson ofereceu 
uma visão ampla do processo, desde os primórdios do capitalismo, assim como desenhou uma trajetória de história política a serviço das estratégias de campanhas e movimentos sociais de que foi contemporâneo.

Polêmico, Thompson recebeu críticas por seu insistente apego ao legado do "inglês nascido livre" ou a uma tradição popular libertária, atitude insuficiente para compreender ou propor açóes em face de um momento radicalmente novo do capitalismo. Como aponta Cardoso (apud MÜLLER, 2002, p. 252-253), Thompson não percebeu a gestação da ideologia neoconservadora nos Estados Unidos (basicamente entre os anos 1970 e 1980), logo estendida ao Reino Unido. Ironicamente, outros autores insinuam "[...] que durante todo o tempo Thompson teria sido um pós-estruturalista clandestino” (SCHWARZ, 1995, p. 24-25).

Membro do Grupo de Historiadores do Partido Comunista Britânico, Thompson deixou o partido após "os acontecimentos de 1956" , seguindo uma vida de militância até sua morte. Para Thompson, a noção de dissenso implicou, em um primeiro momento, um embate com as tendências comunistas ortodoxas e suas definiçóes dogmáticas. Contra elas, propôs a análise dos sujeitos envolvidos na construção de seus próprios destinos e a ideia de um continuum para o socialismo na trilha do legado de luta da classe trabalhadora - de seus "antecedentes" históricos, como os movimentos de oposição ao governo de Walpole, na década de 1720 , até a resistência pacifista pelo desarmamento nuclear e à administração de Margareth Thatcher na década de 1980 .

Apesar de sua importância, essas não seriam razões suficientes para trazermos Thompson a esse debate. Há motivos ainda mais pertinentes. Thompson nos diz respeito, particularmente, porque seu pensamento é uma defesa da razão e dos fundamentos ontológicos do real e, portanto, forte contraponto ao ceticismo epistemológico corrente, à visão relativista que nega a possibilidade do conhecimento objetivo e ao atual anti-realismo e suas promessas de consciências (e ciências) mais pragmáticas (DUAYER, 2003). Mostramos que as proposiçóes thompsonianas, que têm a disciplina histórica como referência, podem orientar a reflexão acerca da pesquisa sociológica e dos problemas do mundo contemporâneo. Em The Poverty of Theory (A Miséria da Teoria), por exemplo, Thompson (1978, p. 217, grifos do autor) afirma: "Este é um tempo em que a razão deve ranger os dentes. À medida que o mundo se modifica, devemos aprender a modificar nossa linguagem e nossos termos. Mas nunca deveríamos modificá-los sem razão". 
Nessas circunstâncias, os objetos da pesquisa sociológica, sem perder seu caráter específico, só ganham inteligibilidade se forem compreendidos em seu movimento histórico. É esta percepção de pesquisa que baliza nossos argumentos e que nos leva a reconhecer em Thompson um interlocutor privilegiado.

Das inúmeras indicaçóes oferecidas pelo historiador, priorizamos duas: a lógica histórica, sua base onto-metodológica, e a categoria de experiência. Embora se situem no conjunto de sua obra, as apresentamos tal como expostas em The Poverty of Theory - e no debate que suscitou. Ambas são basilares à pesquisa desenvolvida por Thompson, que sempre compreendeu o lugar próprio da empiria e da teoria e jamais abdicou do interesse em investigar os procedimentos mais adequados e confiáveis para se transitar entre elas.

\section{A lógica histórica}

Se o complexo estruturado que é o mundo é social em sua essência, ou, dito de outro modo, é histórico em sua dinâmica e diversidade, e em suas articulações e funções, os argumentos de Thompson sobre o "método lógico de investigação adequado a materiais históricos” têm muito a ensinar. São oito os pontos para a discussão da "lógica histórica" que Thompson (1978, p. 231-242) apresenta em The Poverty of Theory, ${ }^{4}$ aqui resumidos:

- O objeto imediato do conhecimento histórico [...] compreende 'fatos' ou evidências certamente dotados de existência real, mas só se tornam cognoscíveis segundo procedimentos que são e devem ser a preocupação dos vigilantes métodos históricos. (THOMPSON, 1978, p. 231);

- por sua própria natureza, o conhecimento histórico é provisório e incompleto; seletivo (mas nem por isso inverídico); limitado e definido pelas perguntas dirigidas à evidência (e os conceitos que informam tais perguntas) e, dessa forma, só é "verdadeiro" no interior do campo assim definido;

- a evidência histórica possui determinadas propriedades e, nesse sentido, embora "[...] lhe possam ser formuladas quaisquer perguntas, apenas algumas serão adequadas" (THOMPSON, 
1978, p. 231-232). Sendo assim, são falsas todas as teorias que não estiverem em conformidade com as determinaçóes da evidência.

Em outro momento do texto, Thompson (1978, p. 199) especifica:

Se isolarmos a evidência singular para um exame à parte, ela não permanece submissa, como a mesa, ao interrogatório: agita-se, nesse meio tempo, ante nossos olhos. Essas agitaçôes, esses acontecimentos, se estão dentro do "ser social", com freqüência parecem chocar-se, lançar-se sobre, romper-se contra a consciência social existente. Propóem novos problemas e, acima de tudo, dáo origem continuadamente à experiência.

Dos juízos anteriores, Thompson (1978, p. 232 grifos do autor) conclui que a relação entre o conhecimento histórico e seu objeto não pode estabelecer que um deles seja função (inferência, revelação, atribuição, etc.) do outro. Em suas palavras: "A interrogação e a resposta são mutuamente determinantes e a relação só pode ser compreendida como um diálogo".

Seu quinto argumento sinaliza o solo ontológico de sua proposta. Ali ele assevera que o objeto do conhecimento histórico é a história "real", cujas evidências serão necessariamente sempre incompletas e imperfeitas. Müller (2002, p. 165) salienta que, embora Thompson, em The Poverty..., não se refira ao pensamento pós-moderno ou ao pós-estruturalista, naquele momento já bastante divulgados e aceitos no mundo acadêmico francês e no de outros países, ele estabelece uma importante demarcação em relação a um dos principais argumentos dessas correntes, qual seja, a de negar o estatuto ontológico do real e a de sua inteligibilidade, isto é, o de negar a própria história. Para Thompson (1978, p. 232-233), haverá sempre novas formas de interrogar as evidências ou de trazer à luz alguns ou muitos de seus aspectos desconhecidos, e, nesse sentido, o produto da investigação histórica estará sempre sujeito a modificaçóes, com as preocupaçóes de diferentes geraçóes ou naçóes, de cada sexo, cada classe social. Isso não significa, no entanto, que os acontecimentos passados se modifiquem ao sabor de cada interrogação investigativa ou que a evidência seja indeterminada. Bem ao contrário, sublinha:

Supor que um "presente", por se transformar em 
"passado", modifica com isso seu status ontológico, é compreender mal tanto o passado como o presente. A realidade palpável de nosso próprio presente (transitório) não pode de maneira alguma ser modificada porque está desde já se tornando passado, para a posteridade [...] Embora os historiadores possam tomar a decisão de selecionar essas evidências [...], o objeto real continua unitário [...] Os processos acabados de mudança histórica, com sua complicada causação, realmente ocorreram, e a historiografia pode falsificar ou não entender, mas não pode modificar, em nenhum grau, o status ontológico do passado. $\mathrm{O}$ objetivo da disciplina histórica é a consecução dessa verdade da história. (THOMPSON, 1978, p. 232; grifo no original).

De acordo com Thompson (1978, p. 235), a investigação da história como processo - ou "desordem racional" - supóe que o pesquisador recorra a "[...] noções de causação, de contradição, de mediação e de organização (às vezes de estruturação) sistemática da vida social, política, econômica e intelectual". Por certo, continua, se tais noçóes são refinadas no interior de procedimentos teóricos, "[...] não é verdade que a teoria pertença apenas à esfera da teoria”, e os procedimentos empíricos cumprem importante papel no processo.

Todos os elementos da pesquisa devem ser decodificados pela teoria apropriada e sujeitos às propriedades determinadas da evidência. Em suas palavras: "Na medida em que uma tese (o conceito ou hipótese) é posta em relação com suas antíteses (determinação objetiva não-teórica) e disso resulta uma síntese (conhecimento histórico)", a decorrência é a "dialética do conhecimento histórico". Uma hipótese testada pelas evidências, e não tendo sido negada por nenhuma contraprova, emerge como conhecimento verdadeiro. Para Thompson, o diálogo entre hipótese e evidência é a base da pesquisa histórica.

Thompson (1978, p. 236) prossegue e demonstra que a diferença entre o materialismo histórico e outras linhas de interpretação das evidências históricas não reside em quaisquer premissas epistemológicas, mas no caráter de totalidade das hipóteses adotadas e na permanente crítica a que são submetidas. Ademais, tal distinção pode ser identificada "[...] por suas 
categorias, suas hipóteses características e procedimentos conseqüentes e no reconhecido parentesco conceitual entre estas e os conceitos desenvolvidos pelos praticantes marxistas em outras disciplinas". Expressando sua crítica a Althusser, ele ressalta que a historiografia marxista não depende de uma "Teoria” localizada em uma parte qualquer, mas, pelo contrário, “[...] a pátria da teoria marxista continua onde sempre esteve, no objeto humano real, em todas as suas manifestaçóes".

Para Thompson, dessa forma, é tarefa do pesquisador explicar um evento em como e por que ele se moveu em uma determinada direçáo e os princípios e tendências fundamentais do processo:

Essa totalidade não é uma "verdade" teórica acabada (ou Teoria); mas também não é um "modelo" fictício; é um conhecimento em desenvolvimento, [...] embora provisório e aproximado, com silêncios e impurezas. O desenvolvimento desse conhecimento se dá [...] na teoria e na prática: surge de um diálogo e seu discurso de demonstração é conduzido nos termos da lógica histórica. (THOMPSON, 1978, p. 242; grifo no original).

No último argumento, Thompson (1978, p. 239-242) apresenta sua restrição fundamental aos estruturalismos (como o de Althusser) e modelos funcionalistas. Nesse oitavo ponto, encontram-se alguns de seus mais conhecidos aforismos, que póem em relevo sua compreensão de pesquisa e de lógica histórica. Por exemplo: "A história em si é o único laboratório possível de experimentação e nosso único equipamento experimental é a lógica histórica”; ou "O materialismo histórico emprega conceitos (gerais e elásticos) mais como expectativas do que como regras"; ou "A história não conhece verbos regulares". Vivemos, diz Thompson (1978, p. 240), em um mesmo "[...] elemento (um presente tornandose passado), um elemento humano de hábitos, necessidades, razóes, vontades, ilusôes, desejos, e deveríamos saber que ele é constituído de um material resistente". O sentido de vencer essa resistência e apreender o elemento humano em suas determinaçóes é dado pela própria história - a realidade concreta -, pois ela é seu próprio laboratório de processo e resultado.

É sobre este solo ontológico que a categoria de experiência é por ele 
formulada, fortemente articulada a uma outra, a de cultura. Essa relação, tal como pensada por Thompson, também se constitui em interesse para a pesquisa sociológica.

\section{Experiência e cultura}

Após alguns séculos ocupando um lugar secundário no âmbito da Filosofia, a ontologia, desde o século XX, retomou seu importante lugar nas discussóes filosóficas. A questão sobre "o que é" - a questão do ser - tornou-se cada vez mais presente quando se pergunta sobre "o como" conhecer. Nessa constatação aparentemente tão simples, expóe-se a radicalidade da ontologia, bem como se evidencia sua relevância para a pesquisa. Isto porque, tenha-se ou não consciência desse fato, a resposta do pesquisador à questão "o que é a realidade?" fundamenta sua compreensão do que são o conhecimento e a ciência e, dessa forma, determina seus pressupostos e direciona seu próprio processo de pesquisa (MORAES, 2000). Hoje, poucos questionam, por exemplo, que toda e qualquer prática humana, inclusive a ciência, pressupóe uma imagem, uma compreensão ou uma crença sobre o mundo, ou seja, uma ontologia, o que está longe de significar qualquer relativismo ou nivelamento entre elas. A negação da ontologia não apenas torna as práticas humanas incompreensíveis, como efetivamente equipara as várias concepçóes sobre o mundo, impede a crítica e favorece o conservadorismo político. É nesse contexto, a nosso ver, que se situa a discussão sobre a experiência desenvolvida por Thompson.

A categoria de experiência, em sua articulação com a de cultura, talvez seja um dos marcos teóricos mais controversos no âmbito da obra thompsoniana. Alguns intérpretes a compreenderam como sendo de natureza superestrutural: a ênfase exagerada na experiência teria conduzido Thompson a descuidos em relação a categorias econômicas e à sobrevalorização de aspectos culturais, como se ele se esquivasse das determinaçóes materiais. Outros, como Hall (1981, p. 383-384), por exemplo, enxergam um caráter empirista na experiência, o que comprometeria a discussão teórica no interior do marxismo. Há ainda os que vêem nele o ponto inicial de um traço culturalista na historiografia (PEDRO; FLORES, 1995, p. 32), hipótese partilhada por Bryan Palmer, para quem Thompson teria contribuído para a progressiva "instalação" dos estudos culturais na História Social (PALMER, 
1990, p. 14). Há até os que consideram os referenciais teóricos de Thompson uma "engenhoca" a ser superada pelo giro linguístico e, ao mesmo tempo, desqualificam esses referenciais como uma "[...] fórmula familiar que seduziu toda uma geração" (JOYCE, 1994, p. 3-4). Algumas dessas leituras favorecem a "desmarxização" de suas ideias (MÜLLER, 2002, p. 17), o que, a nosso ver, força uma reorganização ontológica e epistemológica de seu pensamento. ${ }^{5}$

Nessa parte do artigo, estudamos os fundamentos dos conceitos thompsonianos de experiência e cultura, e seu percurso, identificando-os em suas diferentes relações, e analisamos sua relevância como categorias de análise. Sempre que pertinente, procuramos incluir o conceito de classe no debate ou análise.

Sistematizamos os argumentos em que Thompson propôs aproximaçóes entre a História e a Antropologia, como também o caráter de suas críticas à Sociologia funcionalista e às influências do estruturalismo - a seu ver, algumas vezes perversas - para definir um campo de articulação conceitual entre experiência e cultura, sem perder de vista o processo em sua materialidade histórica.

Thompson procurou estabelecer o uso de conceitos de maneira coerente com a prática do materialismo histórico, delimitando-os de forma a estabelecer "pontes teóricas" entre as diversas disciplinas, buscando um diálogo entre as Ciências Sociais, como já comentamos.

Nesse sentido, quando se refere à controvérsia levantada por Clifford Geertz sobre o trabalho de Keith Thomas, Thompson (2001, p. 229) afirma que "categorias ou 'modelos' derivados de um contexto precisam ser testados, refinados e, talvez, redefinidos no curso da investigação histórica”. Em uma crítica ao reducionismo econômico, Thompson (2001, p. 207) comenta que, apesar de herdar uma "dialética legítima", a análise da base material/ superestrutura não pode desconsiderar "a autonomia dos acontecimentos políticos ou culturais" - mesmo que estes sejam, em última análise, "condicionados pelos acontecimentos 'econômicos"' (THOMPSON, 2001, p. 207). Em suas palavras:

Quando se estabelece uma conexáo ou uma relação causal entre acontecimentos determinados (da ordem da superestrutura) e uma certa configuração de 
interesses de classe (da ordem da base), pensa-se que as exigências da explicação histórica foram satisfeitas porque esses acontecimentos foram caracterizados como burgueses, pequeno-burgueses, proletários etc. O erro não está em estabelecer essas relaçóes, mas em sugerir que as idéias ou os acontecimentos são, por sua natureza, redutíveis ao contexto causal que os explica. [...] Nessas demarches da análise histórica ou sociológica (ou política), é essencial (assumir) o fato de os fenômenos sociais e culturais não estarem "a reboque", seguindo os fenômenos econômicos a distância: eles estão, em seu surgimento, presos na mesma rede de relaçóes. (THOMPSON, 2001, p. 208-209).

A prática do materialismo histórico para Thompson foi, como estrutura real e como metodologia, fonte renovadora para uma teoria da emancipação humana, para uma história escrita a partir de baixo que "[...] representava a constante renovação dos valores de uma cultura de dissidência”, como lembra Müller (2002, p. 5).

É dentro da perspectiva de uma ciência que propõe não só o entendimento, mas também a elaboração de projetos e análises que sirvam de contraponto às práticas dos sistemas dominantes, que a abordagem from below de Thompson permanece necessária e atual. A elaboração de uma história a partir de baixo, vinculada ao estudo das práticas socioculturais de seus representantes, revela-se coerente com uma das teses de Marx, a Tese 11 sobre Feuerbach: "Os filósofos apenas interpretaram o mundo de forma diferente, [porém] o que importa é mudá-lo” (MARX ; ENGELS, 1999, p. 14).

Ao afirmar que “[...] o que costumava ser história operária pode, de fato, constituir excelente terreno de teste para a sociologia histórica", Thompson alerta que é preciso cuidar para que isso não signifique "[...] a desajeitada retomada de uma terminologia mal digerida e de categorias de uma determinada escola sociológica impostas ao conhecimento histórico existente". Ele sugere (2001, p. 191), ao contrário, que seja praticada uma "interpretação mútua" das disciplinas por meio da qual o historiador encontre novas problemáticas para a pesquisa sociológica, simultaneamente fertilizando sua própria pesquisa com uma concepção embotada de conceitos 
sociológicos sem deixar de ser "[...] arredia diante de categorias sociológicas, obtendo, enfim, resultados que (espera-se) possam, por sua vez, adicionar uma dimensão histórica à teoria sociológica” ${ }^{6}$

Sobre essa tendência ao diálogo entre as disciplinas das Ciências Sociais encontrada em estudos sobre a classe trabalhadora, por exemplo, Thompson (2001, p. 199-200) afirma que "[...] há uma preocupação crescente em investigar as manifestaçóes políticas e sociais não incluídas na linha oficial da evolução do movimento operário".

Por um lado, há uma gama de diferentes questionamentos e abordagens que surgem com o intercâmbio entre a História, a Sociologia e a Antropologia. De outro, o estudo histórico faz-se necessário para que a ideia de processo e transformaçáo se torne mais evidente nos estudos sociológicos, sem o que se esvazia a noção de práxis.

Uma sociologia que não contemple em sua reflexão a idéia de processo é fadada a ser uma sociologia na qual os "fenômenos" sociais já aparecem funcionais, estabelecidos e sem aparente mobilidade, porque, no lugar de relacionar o conjunto de normas, práticas, interesses e condiçóes materiais de determinada sociedade em sua dinâmica, parte de um pressuposto sincrônico. O papel da dimensão histórica nessa equação (em seu teor diacrônico, dialético e comparativo) seria o de apontar as transformaçóes e rupturas nas instituiçóes sociais e nos sistemas de organização social e suas possíveis contradiçôes internas.

Ao enfatizar o "processo ativo" mediante o qual o ser humano faz sua história, Thompson (1998, p. 17) aponta para o cuidado a ser tomado ao se generalizar a cultura como um "[...] sistema de atitudes, valores e significados compartilhados, e as formas simbólicas (desempenhos, artefatos) em que se acham incorporados" porque:

Cultura também é um conjunto de diferentes recursos, em que há sempre uma troca entre o escrito e o oral, o dominante e o subordinado, a aldeia e a metrópole; é uma arena de elementos conflitivos, que somente sob uma pressão imperiosa - por exemplo, o nacionalismo, a consciência de classe ou a ortodoxia religiosa predominante - assume a forma de um "sistema". E na verdade o próprio termo "cultura", com sua invocação confortável de um consenso, 
pode distrair nossa atenção das contradiçóes sociais e culturais, das fraturas e oposiçóes existentes dentro do conjunto.

A cultura popular de uma época, por exemplo, só pode ser entendida se contextualizada nos momentos históricos específicos a que pertence. Situando a cultura "no lugar material que lhe corresponde", podemos entendê-la como agente formador, ao mesmo tempo em que é consequência da luta e da consciência de classe.

É nesse tempo/espaço material específico que cultura e experiência se entrecruzam, na consolidação e defesa de interesses e direitos, unindo fragmentos de antigas estruturas e expectativas em relação à luta contra a intrusão verticalizada de novas formas de desapropriação.

A dimensão histórica desse cruzamento aparece em cores vívidas, quando analisamos as queixas de uma larga parcela da população inglesa do séc. XVIII, indignada com as "práticas do mercado", práticas que, comenta Thompson (1998, p. 158), tendemos a admitir como inevitáveis e "naturais".

$\mathrm{O}$ argumento dos que se opunham às práticas exercidas pelos fazendeiros e produtores de grãos daquela época se apoiava na ideia de que, mesmo que fosse mais ou menos óbvio ou "natural" o direito à livre manipulação de algo que lhe pertence, este exercício não era cívico. $\mathrm{O}$ cunho moral de tais reclamaçóes reiterava-se no costume e na tradição simbólica de uma vida em sociedade regrada por um modelo paternalista em franca decadência.

Partindo da lógica de que uma reação ou prática específica de determinada cultura náo pode ser explicada apenas por seu estímulo primordial (conclusão apressada, muitas vezes imposta por estudos estatísticos praticados por vertentes mais conservadoras da História e da Sociologia), Thompson (1998, p. 208) afirma que "[...] não há uma única reação simples, 'animal' à fome", por exemplo. As evidências tornamse inteligíveis se articuladas às especificidades de cada caso. Utilizando ainda o exemplo da revolta causada pela fome, "[...] o 'motim'... não é uma resposta 'natural' ou 'óbvia”, mas antes consiste em “[...] um padrão sofisticado de comportamento coletivo, uma alternativa coletiva a estratégias individualistas e familiares de sobrevivência". Ter fome, comenta, "[...] não impóe que eles devam se rebelar nem determina as formas da revolta”. É a experiência humana forjada nos laços socioculturais que determina, em 
última instância, o resultado, seja do estímulo, seja do malogro em questão.

A questão metodológica levantada por Thompson (1998, p. 151) em relação a esse tipo de problema é de natureza antropológica: "[...] estando com fome [...], o que as pessoas fazem?”. Pode-se acrescentar outra pergunta: diante da fome ou da sensualidade eminente, que relaçóes se estabelecem entre o estímulo material e os desdobramentos das atitudes levadas a cabo em tal situação quando comparados às consequências e reverberaçóes na cultura e nos costumes de seus praticantes?

Thompson (2001, p. 229) reconhece a influência que herda da inquietação antropológica quando a descreve como um estímulo que

[...] se traduz primordialmente não na construção do modelo, mas na identificação de novos problemas, na visualização de velhos problemas em novas formas, na ênfase em normas (ou sistemas de valores) e em rituais, atentando para as expressivas funçôes das normas de amotinação e agitação, assim como para as expressóes simbólicas de autoridade, controle e hegemonia.

Porém, a forma com que Thompson se aproxima dessa problemática é cautelosa (LIMA, 2008).

No processo dinâmico da história, segundo Thompson (2001, p. 248), "novos fenômenos" "acontecem, e sua organização estrutural diante do conjunto se transforma à medida que muda a estrutura das sociedades. Transpor conclusóes antropológicas sem os devidos ajustes compromete o exercício da análise dialética. Assim sendo, "[...] há de se encontrar a estrutura na particularidade histórica do 'conjunto de relaçóes sociais' e não em um ritual ou em uma forma particular fora dessas relaçôes", advindos de outra conjuntura sociocultural. Entretanto, a utilização de tipologias sincrônicas (tipos ideais, funçóes constantes e estruturas universais) é ferramenta útil, seja para trazer à tona, seja para discutir "o âmago de um contexto particular", ao auxiliar a elaboração de uma problemática ou contribuir para o entendimento de tal contexto.

Para Thompson (2001, p. 249), essas tipologias são importantes não por serem estruturas universais, mas "particularmente pelo fato de as funçóes imediatas do ritual" que definem "serem dinâmicas".

Thompson (2001, p. 252) assinala que a relação entre História e 
Antropologia deve ser mediada pela Filosofia, de modo que esta regule os enlaces a serem estabelecidos e não se tenha "[...] a pretensão de falar pelo conjunto da disciplina”, mas "[ ...]apenas fazê-lo a partir de uma posição específica”, para que os resultados da aproximação não sejam contraditórios.

Ao definir-se como filiado à tradição marxista, Thompson (2001, p. 252) reitera que, para se valer de conceitos sociológicos, é necessário que antes estes sejam "[...] revestidos com uma ambivalência ${ }^{8}$ dialética":

Um "ato de doar" deve ser simultaneamente visto como um "ato de ganhar"; o consenso social, como hegemonia de classe; o controle social (muito frequentemente) como controle de classe; e algumas (ainda que nem todas) regras como necessidades.

Em contrapartida, para estabelecer um vínculo entre a Antropologia Social e a História, é preciso, segundo ele, abandonar a perspectiva de "base" e "superestrutura", pela qual, dentro da tradição marxista mais ortodoxa, o "econômico" vem sempre antes das normas e sistemas de valores. Nesse contexto, o princípio de "vir antes" esvazia ou compromete a lógica histórica e a noção de processo, porque se contrapóe à ideia dialética de determinação e denota um sentido de ordem, evolução e irreversibilidade.

Em lugar de adotarmos a premissa de primazia do "econômico", devemos enfatizar "[...] a simultaneidade da manifestação de relaçóes produtivas particulares em todos os sistemas e áreas da vida social”. Sem colocar em dúvida a centralidade do modo de produção (e as subsequentes relaçóes de poder e propriedade) para qualquer compreensão materialista da história, Thompson questiona a ideia de ser possível descrever um modo de produção em termos "econômicos", pondo de lado, como secundárias (menos "reais"), as normas, a cultura, os decisivos conceitos sobre os quais se organiza um modo de produção (THOMPSON, 2001, p. 254).

As nuances particulares constituintes dessa ou daquela sociedade não se encaixam na analogia estática "base e superestrutura" que, no seu determinismo ou reducionismo econômico, classifica "atividades e atributos humanos" ou como pertencentes à "superestrutura (lei, arte, religião, 'moralidade')" ou à “[...] base (tecnologia, economia, ciências aplicadas), deixando outros ainda a flanar no meio (lingüística, disciplina de trabalho)", de forma a pender mais para "[...] o pensamento positivista e utilitarista, 
isto é, com posições centrais não do marxismo, mas da ideologia burguesa" (THOMPSON, 2001, p. 256).

Pensar o "econômico" como determinante, mesmo que apenas em "última instância”, das relações sociais dos indivíduos, é resignar o estudo das sociedades à inércia do ideal do "homem econômico" da Economia Política. Este é um ponto relevante na interpretação thompsoniana da relação base/superestrutura. Muitas vezes, ele explicita sua forte recusa a uma prioridade causal da base, determinista, própria às "versóes reducionistas e economicistas do marxismo" (THOMPSON, 2001, p. 258-260). E aponta para o equívoco da tradição marxista de confundir o "conceito de modo de produção [...] com uma acepção estreita de 'econômico". Sua proposta é a de retornar ao conceito de modo de produção - objeto central da análise de Marx -, que também "[...] oferece as conseqüentes relaçóes de produção, nas quais homens e mulheres nascem ou involuntariamente ingressam". Nesse contexto, a experiência de homens e mulheres existentes se transforma, quando mudam o modo de produção e as relaçóes produtivas.

Nessas circunstâncias, "[...] homens e mulheres, ao se confrontar com as necessidades de sua existência, formulam também seus próprios valores e criam sua cultura própria, intrínsecos a seu modo de vida" (THOMPSON, 2001, p. 261). É nesse sentido que Thompson (2001, p. 260) afirma que classe "[...] é uma formação tão 'econômica' quanto 'cultural"” e que a determinação "em última instância" pode abrir "seu caminho tanto por formas econômicas quanto culturais”.

Como categoria, classe não é representada por este ou aquele grupo de pessoas e instituiçóes com interesses díspares; é antes o modo pelo qual a relação dialética entre os sujeitos opera. Não é a máquina, mas sim “[...] a maneira pela qual a máquina trabalha uma vez colocada em movimento" (THOMPSON, 2001, p. 169). No atrito dessa movimentação, formam-se as "condiçóes materiais" que, por sua vez, influenciam a experiência que, aqui, aparece como um "termo médio", necessário na articulação entre ser social e consciência social. Por isso, não há sentido de se pensar "classe" como categoria de análise, se não for levada em conta a mediação entre o "agir humano" (agency) e a realidade a ser acionada no processo histórico de transformação da cultura, da consciência e das "condiçóes materiais" que a impulsionaram.

A consequência imediata da utilização do conceito de "experiência" 
nos estudos da sociedade é encarar homens e mulheres não apenas como sujeitos atomizados, individualizados e separados de um contexto nem considerá-los como simples "turba" ou massa, mas acima de tudo como

Pessoas que experimentam suas situaçóes e relaçóes produtivas determinadas como necessidades e interesses e como antagonismos, e em seguida (lidam com) essa experiência em sua consciência e sua cultura [...] das mais complexas maneiras (sim, "relativamente autônomas") e em seguida (muitas vezes, mas nem sempre, através das estruturas de classe resultantes) agem, por sua vez, sobre sua situação determinada. (THOMPSON, 1978, p. 356).

Segundo Thompson (1978, p. 290), “[...] é a experiência (muitas vezes a experiência de classe) que dá cor à cultura, aos valores e ao pensamento”. É pela mediação da experiência "[...] que o modo de produção exerce uma pressão determinante sobre outras atividades” e regula a prática pela qual a produção é mantida e reproduzida.

Thompson (1981a, p. 405) afirma que “[...] a experiência é exatamente aquilo que faz a junção ${ }^{9}$ entre a cultura e a não-cultura, estando metade dentro do ser social, metade dentro da consciência social". A experiência é também "a influência do ser social sobre a consciência social", na medida em que "[...] exerce pressóes sobre a consciência social existente", propóe novas questóes e proporciona "[...] grande parte do material sobre o qual se desenvolvem” (THOMPSON, 1978, p. 196, 200-201).

A "experiência" realiza o diálogo ${ }^{10}$ entre o ser social e a consciência social, uma vez que "[...] assim como o ser é pensado, também o pensamento é vivido" (THOMPSON, 1978, p. 200-201). Segundo Thompson (1978, p. 201), mudanças no ser social dão origem à "experiência" que, por sua vez, tem o papel determinante de mediar o processo de transformação da consciência social. É mediante esse diálogo que podemos estabelecer uma correspondência entre o conhecimento e as propriedades "inscritas" na realidade material (THOMPSON, 1978, p. 209).

Nesse sentido, a "experiência" é fator indispensável na análise da 
História ou de qualquer disciplina que abrace uma perspectiva diacrônica e/ou dialética porque é um conceito que "compreende a resposta mental e emocional" de um indivíduo ou determinado grupo social "[...] a muitos acontecimentos inter-relacionados ou a muitas repetiçóes do mesmo tipo de acontecimento" (THOMPSON, 1978, p. 199).

Foi em um Seminário realizado em Oxford sobre The Poverty..., em dezembro de 1979, um ano após sua publicação na Inglaterra ${ }^{11}$, que Thompson ofereceu importantes esclarecimentos sobre a relação entre experiência e cultura em resposta às críticas dos demais expositores. Precisando sua posição, Thompson propóe a distinção entre dois níveis de experiência: a experiência I - a experiência vivida - e a experiência II - a experiência percebida. Resumiremos, nesse espaço, os aspectos destacados por seus críticos, bem como os pontuados por Thompson no debate, associados, quando necessário, a seus argumentos em The Poverty....

Stuart Hall (1981, p. 384) argumenta que a forma pela qual Thompson define "experiência" em dois momentos náo é adequada porque "[...] combina coisas que... 'na realidade' (na experiência vivida) ocorrem juntas, mas que têm que ser, analiticamente, distinguidas”. Hall comenta que a tentativa de Thompson de sobrepujar esse problema "[...] falando de duas 'experiências' - experiência I (condiçóes) e experiência II (como estas são anexadas à consciência)" é teoricamente insatisfatória. Segundo Hall, “[...] não se facilita o difícil processo de pensar a relação entre dois termos nomeando-os com o mesmo conceito", porque isso simplesmente confundiria distinçóes que devem ser conceitualmente separadas.

Acusaçôes mais graves são efetuadas por Richard Johnson (1981, p. 386-396), ao definir como revisionista e um "absolutismo" teórico a atitude de Thompson em relação a Althusser, a seu ver uma atitude que mais subtrai do que agrega para a construção de posiçôes sólidas dentro da tradição marxista. Nessa empreitada, Johnson atua mais como político do que cientista.

Thompson é incisivo ao refutar o suposto caráter culturalista de sua obra e ao reafirmar a categoria de experiência nos termos materialistas originalmente por ele propostos. Não aceita a acusação de Richard Johnson de que teria interpretado à luz da cultura a categoria marxista de consciência de classe e contribuído para fortalecer os estudos culturais com seu The Making of the English Working Class (1980). Em suas palavras: "Rejeito, 
incondicionalmente, o título de 'culturalismo' dado à tradição historiográfica marxista da qual sou considerado representante" (THOMPSON, 1981, p. 396). No quadro de seu materialismo histórico, o conhecimento de classe seria impossível sem a compreensão das experiências que emergem dos confrontos entre classes em função também das diferenças entre as várias culturas, políticas, religião, valores, convençóes, etc.

Thompson (1981, p. 401) recorda que, no início dos anos 1960 (quando para Johnson o "culturalismo" teria se estabelecido), ele estava a meio caminho da conclusão de The Making... e que esse período se caracterizou pelas polêmicas a respeito do stalinismo, do humanismo socialista e da história econômica positivista, bem como pela crítica - e não a adesão - ao culturalismo. À época, os temas cultura e experiência eram alvo de troca - e disputa - intelectual entre ele e Raymond Williams, entre outros. Thompson menciona um trecho no qual critica Williams e reafirma a base ontológica, a lógica histórica - o processo mediante o qual os seres humanos fazem sua história - como determinação do campo cultural:

Toda teoria da cultura deve incluir o conceito da interação dialética entre cultura e algo que não é cultura. Devemos supor que a matéria-prima da "experiência de vida" esteja em um dos pólos, e todos os infinitamente complexos sistemas e disciplinas humanos, articulados ou não, formalizados em instituiçôes ou dispersos das maneiras menos formais que "manejam", transmitem ou distorcem esta matéria-prima, estejam no outro pólo. É sobre este processo ativo, que é, ao mesmo tempo, o processo mediante o qual os seres humanos fazem sua história, que venho insistindo. (THOMPSON, 1981, p. 398; grifo no original).

Thompson responde, assim, à crítica de que, por exemplo, no capítulo "Exploração", de The Making..., teria subsumido a "exploração" à "experiência da exploração", rejeitado causas materiais que ocorrem concomitantemente à consciência e dissociado a consciência de suas determinaçóes concretas.

Experiência e cultura são articuladas por Thompson (1978, p. 362), e ambas constituem um ponto de junção entre estrutura e processo, entre as determinações objetivas do ser social e a possibilidade de ação e intervenção 
humanas. ${ }^{12}$ Neste sentido, são "conceitos de junção" (junction-concepts). Para Thompson, homens e mulheres atuam e constroem suas vidas em condiçóes determinadas e vivem esta experiência tanto no âmbito do pensamento como no do sentimento. Na cultura, ele afirma (1978, p. 363), os sujeitos lidam com o sentimento como normas, obrigaçóes familiares e de parentesco e reciprocidades, como valores, ou mediante formas mais elaboradas na arte ou nas convicçóes religiosas. Ele continua:

Os valores não são apenas "pensados", nem "chamados"; são vividos e emergem no interior do mesmo vínculo com a vida material e as relaçôes materiais em que surgem nossas idéias. São as normas, regras, expectativas etc., necessárias e aprendidas (e "aprendidas" no sentimento), no habitus de viver; e aprendidas, em primeiro lugar, na família, no trabalho e na comunidade imediata. Sem esse aprendizado a vida social não poderia ser mantida e cessaria toda produção. (THOMPSON, 1978, p. 367).

Como vimos, Thompson (1981, p. 405-406) distingue entre experiência I - experiência vivida - e experiência II - experiência percebida. Muitos epistemólogos e sociólogos contemporâneos, diz Thompson, quando ouvem a palavra "experiência", identificam-na imediatamente à experiência II, a experiência percebida. Isto é, movem-se na direção do que Marx denominou consciência social. Como consequência, afirmam que a "experiência II" é um meio imperfeito e falsificador, corrompido por interferências ideológicas, etc.

Thompson observa que as regularidades no interior do ser social, com frequência, resultam de causas materiais que ocorrem de forma independente da consciência ou da intencionalidade. Tais causas inevitavelmente dão ou devem dar origem à experiência vivida, à experiência I, mas não penetram como "reflexos" na experiência II. No entanto, a pressão dessas causas sobre a totalidade do campo da consciência náo pode ser adiada, falsificada ou suprimida indefinidamente pela ideologia. Retomando argumentos expostos em The Poverty..., atesta: 
A experiência chega sem bater na porta e anuncia mortes, crises de subsistência, guerras, desemprego, inflação, genocídio. Pessoas passam fome: os que sobrevivem pensam o mercado de outra forma. Pessoas são presas: na prisão meditam sobre a lei de novas maneiras [...] Dentro do ser social ocorrem mudanças que dão origem a uma experiência transformada: e essa experiência é determinante, no sentido de que exerce pressóes sobre a consciência social existente, propôe novas questóes e oferece grande parte do material com que lidam os exercícios intelectuais mais elaborados. (THOMPSON, 1978, p. 200-201; grifo no original).

Por essa razão, assevera Thompson (1981, p. 406), essa é a única maneira possível de "explicar a mudança histórica com alguma racionalidade": "A experiência I está em eterna fricção com a consciência imposta e, quando ela irrompe, nós, que lutamos com todos os intricados vocabulários e disciplinas da experiência II, podemos experienciar alguns momentos de abertura e de oportunidade, antes que se imponha mais uma vez o molde da ideologia”.

Dessa forma, a experiência, "sem bater na porta”, constitui e nega, opõe e resiste, estabelece mediaçóes, é espaço de prática, intervenção, obstaculização, recusa, é processo de formação de identidades de classe e, poderíamos acrescentar, de gênero, de geração, de etnias. Processos dialeticamente articulados que a experiência expressa de forma privilegiada.

Thompson distancia-se, como se vê, do conceito vulgar de experiência, o que estabelece sua equivalência com a empiria. Mesmo porque, como sublinham Moraes e Torriglia (2000, p. 53), "[...] a construção empirista da experiência induz ao relativismo e à passividade e à aceitação de todo o status quo", posição que está na contramão da proposta intelectual e de vida do historiador.

Thompson se afasta, por outro lado, das interpretaçóes culturalistas do termo e de sua negação de determinaçóes materiais ou estruturais na formação da identidade dos sujeitos sociais. Em contraposição a essas interpretaçóes, Thompson (1978, p. 232-235) indica que, "[...] na medida em que uma noção é endossada pelas evidências, temos então todo o direito 
de dizer que ela existe 'lá fora', na história real”. Há referentes, portanto. O solo ontológico da experiência é a história real, e não a cultura ou a linguagem. Se cultura e experiência são um ponto de junção, a cultura não tem, para Thompson, qualquer autonomia, apesar do que ajuízam adeptos da "pós-condição". Até ser contextualizada, a cultura é altamente problemática como categoria explicativa.

À época da elaboração de The Poverty... (1977-1978), e da realização do debate (dezembro de 1979), Thompson não polemizou com o pensamento pós-estruturalista ou pós-moderno - sequer em suas versóes culturalistas presente nos meios acadêmicos norte-americanos e europeus. Isso se explica pelo caráter conscientemente político da obra ${ }^{13}$, pelo fato de ter sido escrita para a esquerda e para o âmbito do marxismo. O alvo de Thompson situavase na esquerda, os estruturalistas althusserianos, o que ele considerava um risco para a tradição de prática histórica marxista na Inglaterra, devido a seu absolutismo teórico, sua negação do agir humano e a presumida conivência de Althusser com a violência stalinista praticada em nome do marxismo e com "as vastas áreas de silêncio" em torno do Estado soviético.

A crítica de Thompson ao giro linguístico viria mais tarde, no início dos anos 1990, pouco antes de sua morte, já sob o impacto da influência das interpretaçóes culturalistas e linguísticas na história social inglesa. Müller (2002, p. 32-33, 41) destaca dois momentos desta crítica:

- em Customs in Common, referindo-se a Gramsci, Thompson salienta que, para o pensador italiano, a filosofia comum a todas as pessoas deriva de três fontes: a própria linguagem, que é um conjunto de determinadas noçóes e conceitos, e não apenas palavras desprovidas gramaticalmente de conteúdos; o "senso comum" e o folclore ou a religião popular. Das três, conclui: "Hoje a maioria dos intelectuais do ocidente não hesita em conceder primazia teórica à primeira (a linguagem), não só por ser o veículo, mas a influência constitutiva sobre a consciência”. Ele afirma, criticando especificamente a historiografia que adere a tal posição:

Embora a linguagem real - por exemplo, o dialeto tenha sido pouco estudada, entrou na moda presumir que a plebe era em certo sentido determinada pela sua herança lingüística, considerada, por sua vez, um verdadeiro bricolage de idéias díspares, derivadas 
de muitas fontes, mas mantidas no seu lugar pelas categorias patrícias. Os plebeus chegam a serem vistos como prisioneiros da linguagem, compelidos, até mesmo em seus momentos de rebeldia, a moverse dentro dos parâmetros do constitucionalismo, da Velha Inglaterra, da deferência devida aos líderes do patriciado e do patriarcado. (THOMPSON, 1993, p. 10; grifo no original).

- em "Reading the Signs", Samuel (1992, p. 243) comenta um antigo ensaio de Thompson, "The Sale of Wives" (incluído em Customs in Common), e considera que, de certo modo, esse artigo revelaria a adoção da perspectiva pós-moderna por parte de seu autor. Esse comentário causou grande desconforto a Thompson, como se percebe em sua carta-resposta, “Theory and Evidence”, no número 35 de History Workshop, onde lamenta a hesitação teórica de Samuel na abordagem do problema e critica a influência pós-modernista na historiografia:

No momento [a posiçáo de Samuel] varia entre uma aguda e perspicaz análise e uma bem elaborada revisão dos livros da moda. Nessa última posição ele mostra sinais de capitulaçáo - como na passagem que eu critiquei - ao subjetivismo da moda e ao idealismo agora tão corrente. Essa moda parece que vai durar pelo menos uns vinte anos e seria realmente uma pena que Raphael Samuel e History Workshop se submetessem a ela. Triste e totalmente desnecessário, porque a escolha oferecida, um positivismo grosseiro ou um idealismo "plausível", é completamente falsa. Teoria e evidência devem estar sempre em diálogo entre si. (THOMPSON, 1993a, p. 274-275; grifo no original).

Quiçá tardiamente, Thompson compreende que o "subjetivismo da moda", "o positivismo grosseiro" e o "idealismo plausível” são representados pela agenda pós-moderna. Ele percebe a inversão pós-moderna e pósestruturalista que desfoca o lugar e o papel da experiência na construção do conhecimento, dos interesses e das identidades sociais, colocando em 
seu lugar, isoladamente, a linguagem ou a cultura. Müller (2002, p. 30) assinala que seria inadmissível para o historiador aceitar que a experiência fosse "codificada" e aprisionada em um corpus de linguagem e de textos, corpus táo dominante e onipotente que virtualmente a subsumiria. Da mesma forma, o papel de relevo que o historiador atribui à cultura em suas análises históricas distancia-se das acepçóes que lhe têm sido atribuídas por culturalistas de toda cepa.

Nessas circunstâncias, a nosso ver, evidencia-se a radical atualidade de Thompson para os que pensam a pesquisa sociológica para além das empirias compartilhadas, dos relativismos, culturalismos ou construtos discursivos (MORAES; TORRIGLIA, 2000). Ele inspira os que compreendem os fatos sociais como fatos históricos e os que, nessa perspectiva, descartam a teoria como verdade ou modelo fictício e abraçam o desafio do conhecimento como percurso, sempre provisório e aproximado, prenhe de "silêncios e impurezas".

\section{Palavras finais}

É fecunda a proposição thompsoniana de que é tarefa do pesquisador explicar um evento em como e por que ele se moveu em uma determinada direção, e também os princípios e tendências fundamentais deste processo. De nosso ponto de vista, suas reflexóes sobre a pesquisa e sobre a importância do desvelamento das determinaçóes concretas do objeto a ser pesquisado constituem um protocolo apropriado às Ciências Sociais e Humanas.

É estimulante pensar, por exemplo, que uma experiência singular - a migração; a reorganização do processo de trabalho, ou a redefinição da divisão de trabalho e suas relaçóes; o redesenho das classes sociais, ou o do Estado ou o da estrutura de poder em nível internacional, e a correlata revisão da estratégia das relaçóes políticas e econômicas, etc. - náo "permanece submissa” ao ser investigada, mas agita-se dentro do ser social e, neste movimento, rompe-se contra a consciência social prevalecente; que a experiência não se anuncia; exerce pressões; propõe novas questóes e oferece os dados a serem lidos pelos exercícios intelectuais; que o conhecimento é provisório e incompleto, seletivo, limitado e definido pelas perguntas dirigidas à evidência (e os conceitos que informam tais perguntas) e que a verdade só pode ser pensada no interior do campo assim definido; que sempre haverá novas formas de interrogar o objeto ou de evidenciar aspectos 
até então desconhecidos e que, por isso mesmo, o produto da investigação estará sempre sujeito a modificaçóes.

Desta compreensão, não decorre, no entanto, qualquer relativismo ou negação da ontologia, ou "[...] que os acontecimentos passados se modifiquem ao sabor de cada interrogaçáo investigativa ou que a evidência seja indeterminada" (THOMPSON, 1978, p. 232-233). Como destacamos no início, o pensamento thompsoniano é contraponto ao ceticismo epistemológico e aos relativismos ontológicos correntes, à visão relativista que nega a possibilidade do conhecimento objetivo e ao atual antirrealismo.

Para concluir, vale salientar, uma vez mais, a convicção de Thompson acerca do conhecimento, cuja andança se dá na conjugação e no diálogo entre teoria e prática, e seu discurso de explanação é conduzido nos termos da lógica histórica. E por esta razão, ele atesta, a teoria tem consequências, o que não deve ser indiferente aos que pensam e desenvolvem pesquisas no campo das Ciências Humanas e Sociais.

\section{Notas}

1 A primeira edição de The Making of the English Working Class é de 1963, com reediçóes em 1968 e 1980, pela Penguin/Pelican. Em nossos comentários e referências, adotamos preferencialmente as edições originais em inglês.

2 Na edição brasileira, o "Prefácio" compreende as páginas de 9 a 14 do vol. I. Embora lançada em 1987 em três volumes, a edição brasileira não incluiu os "Comentários Bibliográficos" ('Bibliographical Note'); o "Posfácio" à edição de 1968, no qual Thompson responde a críticas recebidas, e o "Prefácio" à reedição de 1980, com observaçóes sobre o percurso do livro até aquele momento e um novo balanço de sua recepção. Para maior precisão, cf. Thompson, E. P. (1980), edição original em inglês.

3 Entre os principais eventos políticos de 1956, destacam-se, por exemplo, o discurso de Khruschev no XX Congresso do Partido Comunista da União Soviética (e a divulgação de um relatório sobre o período de Stalin); as crises do Canal de Suez e a de Chipre, e a invasão soviética da Hungria - a qual, sobretudo, provocou a desfiliação de vários mem- 
bros do Partido Comunista Britânico, como as de Thompson e outros historiadores.

4 Como o descreve Müller (2002, p. 150), trata-se de um texto construído "contra o estruturalismo de Louis Althusser ("O Aristóteles do novo idealismo marxista”, in Thompson, 1978, p. 196).

5 A esse respeito, vale lembrar que também Gramsci, Vigotski e Bakhtin sofreram - e sofrem - investidas similares.

6 Segundo Thompson, exemplos desse tipo de trabalho eram encontrados em periódicos como Comparative Studies in Society and History, Le Mouvement Social, Sociologie et Travail e Economic Development and Cultural Change.

7 Cf. também Thompson (1994, p. 214), em inglês: new features, no sentido de novas formas e características que se desenvolvem no decorrer da dinâmica histórica.

8 Nesse trecho, ambivalência (no original, ambivalence) não significa ambiguidade, mas uma relação de "mão dupla": duas vias, entre positivo e negativo, como os atos de doar e o de receber.

9 Thompson (1978, p. 302 e 355-356) delimita os "conceitos de junção" como pontos de junção, por exemplo: (1) entre disciplinas acadêmicas, nas quais conceitos como "necessidade" em economia podem, reaparecer na Antropologia como "norma" e na História como "vontade" ou "valores"; (2) entre estrutura e processo, como os conceitos de modo de produção" - como "uma pressão determinante dentro de um complexo processo histórico"; (3) o de "classe”, "[...] como a estruturação de um modo de produção ou acontecendo (eventuating) sob formas que nunca podem ser predeterminadas"; (4) e o próprio "determinismo", quando considerado como "fechamento" ou "pressão".

10 Cf. Thompson (1978, p. 201), onde ele afirma que "[...] esse diálogo se processa em ambas as direçóes" e (p. 224-225) sobre "[...] o diálogo entre o ser social e a consciência social, que dá origem à experiência”. Como o ser social não é inerte, "[...] tampouco a consciência social é um recipiente passivo", pois "atua de volta sobre o ser". Thompson (1978, p. 205) resume sua crítica a Althusser nos seguintes termos: "A categoria ganhou uma primazia sobre seu referente material; a estrutura conceitual paira sobre o ser social e o domina”. 
11 Esse encontro fez parte da programação de um Seminário, sob a coordenação de Raphael Samuel, promovido pelo Ruskin College e pelo grupo "History Workshop". Participaram: Stephen Yeo, como presidente do painel; Stuart Hall, com o trabalho "In Defense of Theory"; Richard Johnson, com o texto "Against Absolutism", e E. P. Thompson, com "The Politics of Theory”, no qual responde aos dois debatedores e avança outras questões. Cf. Samuel, Raphael (ed.) (1981), que reproduz o debate no capítulo "Culturalism: Debates around The Poverty of Theory", p. 375-408. Cf. Müller, Ricardo (2002, p. 190 et passim). A propósito, Martin Jay (2006, p. 196, n. 103) acredita que o Ruskin College, em Oxford, é o melhor exemplo de um lócus para a prática da história a partir de baixo, de acordo com as ideias de Thompson. Fundado em 1967, ali funcionou o núcleo do grupo History Workshop, e de seu periódico, e Raphael Samuel foi seu principal líder, até falecer em 1996.

12 Como indica Müller (2002, p. 182, 196), a noção de junction concepts é resultado de um conjunto de discussões entre Thompson e Raymond Williams. Em sua fala, Thompson também incorpora uma leitura crítica da categoria determinação, bem como do conceito de "estruturas de sentimento", desenvolvidos por Williams em Marxismo e Literatura. Cf. Williams (1979, p. 89 e 134-135).

13 Em sua introdução às notas do final do texto, Thompson (1978, p. 385) escreve: "Esse ensaio é uma intervenção política polêmica e não um exercício acadêmico".

\section{Referências}

AHMAD, Aijaz. In our time: empire, politics and culture. London: Verso, 2007.

- Linhagens do presente. São Paulo: Boitempo, 2002. . In theory: classes, nations, literatures. London: Verso, 1992.

ÁVILA, A. B. A pós-graduação em Educação Física e as tendências na produção de conhecimento: o debate entre realismo e anti-realismo. Texto de qualificação (Doutorado em Educação). Florianópolis: PPGE/ Programa de Pós-Graduação em Educação, Universidade Federal de Santa Catarina (UFSC), 2007, $143 f$. 
BHASKAR, R. A Realist theory of science. London: Verso, 1997.

. Scientific realism and human emancipation. London: Verso, 1986.

- Reclaiming reality: a critical introduction to contemporary

Philosophy. London: Verso, 1993.

. Societies. In: . The possibility of naturalism. Brighton:

Harvester Press, 1979.

CALLINICOS, A. The resources of critique. Cambridge: Polity, 2006.

CARDOSO, Ciro F. A história na virada do milênio: fim das certezas, crise dos paradigmas: que história convirá ao século XXI? In: XXI Simpósio Nacional de Historia/ANPUH, Niterói: UFF, 2001. Mimeo. . Ensaios racionalistas. Rio de Janeiro: Campus, 1988.

. Narrativa, sentido e história. Campinas: Papirus, 1997.

DUAYER, M. Anti-realismo e absolutas crenças relativas. Margem Esquerda. São Paulo, v. 8, p. 109-130, 2006.

. Economia depois do relativismo: crítica ontológica ou ceticismo instrumental? In: CONGRESSO DA SOCIEDADE DE ECONOMIA POLÍTICA, 8. Anais... Florianópolis: SEP, 2003.

. Ontologia na ciência econômica: realismo ou ceticismo instrumental? Niterói: UFF, 2003. Trabalho não publicado.

. Marx, verdade e discurso. Perspectiva. Florianópolis: CED/ UFSC, v. 19, n. 1, p.15-39, jan./jun. 2001.

EAGLETON, T. After theory. London: Penguin Books; New York: Basic Books, 2003.

GOLDMANN, L. Dialética e cultura. Rio de Janeiro: Paz e Terra, 1979.

HAACK, Susan. Evidencia e investigación: hacia la reconstrucción en epistemología. Madrid: Tecnos, 1997.

HALL, Stuart. In defence of theory. In: SAMUEL, Raphael (Ed.). People's history and socialist theory. London: Routledge, 1981.

INGLIS, Fred. Radical earnestness. Oxford: Martin Robertson, 1982. 
JAY, Martin. Songs of experience. Berkeley: University of California Press, 2006.

JOHNSON, Richard. Against absolutism. In: SAMUEL, Raphael (Ed.). People's history and socialist theory. London: Routledge, 1981.

JOYCE, Patrick. Democratic subjects. Cambridge: Cambridge University Press, 1994.

LIMA, Luiz César. Classe, cultura e experiência: a inarbitrariedade do ser social. Dissertação de Mestrado em Sociologia Política. Florianópolis: Programa de Pós-Graduação em Sociologia Política, Centro de Filosofia e Ciências Humanas, Universidade Federal de Santa Catarina (PPGSP/ CFH/UFSC), 2008.

LUKÁCS, Georg. Ontologia do ser social: os princípios ontológicos fundamentais de Marx. São Paulo: LECH. 1979.

MARX, K. O capital. Rio de Janeiro: Civilização Brasileira, 1974.

Value, price and profit: an introduction to the theory of capitalism, 1865. Disponível em:< www.marxists.org/archive/marx/works/1865/ value-price-profit/index.htm>. Acesso em: 17 jun. 2007.

MARX, Karl e ENGELS, Friedrich. A ideologia alemã (Feuerbach). 11. ed. S. Paulo: Hucitec, 1999.

MORAES, Maria Célia M. Indagaçóes sobre a questão do conhecimento no campo da educação. In: IV Jornadas de Investigación em Educación; julho de 2007. Córdoba: Universidad Nacional de Córdoba. Conferência principal. Texto não publicado, 2007.

. Proposiçóes sobre produção de conhecimento e políticas de formação docente. In: MORAES, Maria Célia M. et al. Iluminismo às avessas: produção de conhecimento e políticas de formação docente. Rio de Janeiro: DP\&A, 2003.

. Recuo da teoria. Revista Portuguesa de Educação. Braga, Portugal, ano 14, n. 1, p. 7-25, 2001a.

- Ceticismo epistemológico, ironia complacente: até onde vai o neopragmatismo rortyano? Educação nas Ciências. Ijuí, ano 1, n. 1, p. 157-189, jan./jun. 2001 b. 
MORAES, Maria Célia M. Reforma de ensino, modernização administrada: Florianópolis: a experiência de Francisco Campos - anos vinte e trinta. Florianópolis: UFSC/CED/ NUP (Teses NUP, 5), 2000a.

; MÜLLER, Ricardo G. "A miséria da teoria”: o debate de Oxford. Esboços: Revista do Programa de Pós-Graduação em História, Florianópolis, v. 14, p. 25-36, 2005.

MORAES, Maria Célia M.; TORRIGLIA, Patricia L. Educação light, que palpite infeliz. Indagaçóes sobre as propostas do MEC para a formação de professores. Teias. Rio de Janeiro: UERJ, ano 1, n. 2, p. 5159, 2000.

MÜLLER, Ricardo G. Razão e utopia: Thompson e a história. 2002. Tese (Doutorado em História Social). São Paulo: Programa de Pós-Graduaçáo em História Social, Universidade de São Paulo (USP).

NORRIS, C. What's wrong with postmodernism, critical theory and the end of philosophy. Hampstead: Harvester/Wheatsheaf, 1996.

. Treading water in neurath's ship: Quine, Davidson, Rorty.

Principia, Revista Internacional de Epistemologia, Florianópolis, v. 2, n. 2, p. 227-279, dez.1998.

PALMER, Bryan D. Descent into discourse: the reification of language and the writing of social history. Philadelphia: Temple University Press, 1990.

PEDRO, Joana M.; FLORES, M. Bernadete R. História, experiência e narrativa. Revista Catarinense de História 3, Florianópolis: UFSC \& Ed. Insular, p. 29-34, 1995.

SAMUEL, Raphael. Reading the signs (part II). History Workshop Journal, Oxford: Oxford University Press, n. 33, p. 220-251, Mar./May ,1992.

(Ed.). People's history and socialist theory. London: Routledge,

1981.

SCHWARZ, Bill. Razão e desrazão em E. P. Thompson. In:

ANTONACCI, Maria Antonieta (Ed.). Diálogos com E. P. Thompson. São Paulo: PUC/SP, 1995. (Projeto História, 12).

SEARLE, John R. Mind, language and society. New York: Basic Books, 1998. 
SOARES, K. D. Trabalho e conhecimento docentes. Texto de qualificação (Doutorado em Educação). Florianópolis: Programa de Pós-Graduação em Educação, Centro de Ciências da Educação, Universidade Federal de Santa Catarina, 2007. 164f,.

THOMPSON, E. P.. The Making of the English Working Class.

Harmondsworth, Penguin: Pelican Books (com novo Prefácio), 1980. . The poverty of theory and other essays. London: Merlin, 1978. . The politics of theory. In: SAMUEL, Raphael (Ed.). People's history and socialist theory. London: Routledge, 1981.

THOMPSON, E. P. A formação da classe operária inglesa. 2. ed., Rio: Paz e Terra, 1987.

THOMPSON, E. P. Customs in common. New York: New Press, 1993.

Theory and evidence. History Workshop Journal. Oxford: Oxford University Press, n. 35, p. 274-275, Mar/May 1993a. Disponível em: $<$ http://hwj.oxfordjournals.org/cgi/reprint/35/1/274? maxtoshow=\&hits= 10\&RESULTFORMAT = 1 \&author $1=$ THOMPSON\%2C+E.+P.+\&and orexacttitle $=$ and $\&$ andorexacttitleabs $=$ and $\&$ andorexactfulltext $=$ and $\&$ searc hid=1\&FIRSTINDEX=0\&sortspec=relevance\&volume=35\&resourcetyp e=HWCIT $>$. Acesso em: 16 jun. 2009.

. As peculiaridades dos ingleses e outros artigos. NEGRO, Antonio Luigi; SILVA, Sergio (Org.). Campinas: Editora da Unicamp, 2001. THOMPSON, E. P.. Persons \& Polemics: Historical Essays. London: Merlin, 1994.

Costumes em comum: estudos sobre a cultura popular tradicional. São Paulo: Companhia das Letras, 1998.

WILLIAMS, Raymond. Marxismo e literatura. Rio: Zahar, 1979. 


\section{E. P. Thompson and Social Sciences research}

\section{Abstract}

E. P. Thompson did try to drive a relevant dialog among the social sciences by incorporating sociological categories in his historical research and by criticizing functionalist trends in both disciplines. His method for analyzing the making of the working class conveys a simultaneous criticism of the methodological laws and rules of conservative and functionalist social historians and sociologists, and orthodox Marxists as well. The currentness and importance of Thomspon's work are due to the fact that his thinking is a defense of reason and of the ontological foundations of the real, a strong counterpoint to actual anti-realism and epistemological skepticism, and the relativist vision that denies the possibility of objective knowledge. The references for Thompson's proposals are those of the discipline of history and guide a reflection on sociological research and contemporary social-political questions. Thus, the objects of the sociological study can only become understandable if apprehended in their historical movement and, in this sense, they shall not lose their specific character. These are the grounds of the approach of this article and they invite Thompson as a privileged interlocutor.

Key words: Social sciences research. Social interaction.

\section{E. P. Thompson y la investigación en Ciencias Sociales}

\section{Resumen}

E.P Thompson desarrolló un importante dialogo entre las ciencias sociales al incorporar en sus investigaciones históricas categorías sociológicas y al criticar las tendencias funcionalistas de las dos disciplinas: la sociología y la historia. Su método para analizar la formación de la clase trabajadora representa una crítica simultánea a las leyes y reglas metodológicas de historiadores sociales y sociólogos conservadores, funcionalistas y marxistas ortodoxos. La actualidad de la obra de Thompson reside en el hecho de que su pensamiento es una defensa de la razón y de los fundamentos ontológicos de la realidad, un fuerte contrapunto al escepticismo epistemológico, a la visión relativista que niega la posibilidad de conocimiento objetivo y las corrientes ante-realistas. Las proposiciones thompsonianas tienen como referencia a la disciplina histórica orientando las reflexiones de la investigación sociológica y las cuestiones políticas contemporáneas. Así, los objetos de la investigación sociológica, sin estos perder su carácter específico, solamente ganan inteligibilidad si son comprendidos en su movimiento histórico. Esta es la perspectiva que orienta los argumentos de este artículo y reconoce a Thompson como un interlocutor privilegiado.

Palabras clave: Ciencias sociales - Investigación. E. P. Thompson. 


\section{Ricardo Gaspar Müller}

Caixa Postal 5205 - Florianópolis - SC,

CEP: 88040-970

E-mail:muller@cfh.ufsc.brourgmuller@superig.com.br

Recebido em: 2/2/2008

Aprovado em: 19/7/2008 